\title{
Vigencia y potencia de la teoría crítica del derecho
}

Validity and power of the critical theory of law

\author{
Rodrigo Calderón Astete 1 \\ Universidad Pablo de Olavide - España
}

Revista Derechos en Acción ISSN 2525-1678/ e-ISSN 2525-1686

Año 5/No 16 Invierno 2020 (21 junio a 20 septiembre), 756-784

DOl: https://doi.org/10.24215/25251678e442

Recibido: 01/02/2020

Aprobado: 15/05/2020

\section{Introducción}

Sobre todo sus partidarios se preguntan por la vigencia de la Teoría Crítica del Derecho; entre ellos se interrogan por los desafíos actuales, por donde debe ser ubicada en el mapa de la teoría del derecho, si llamarse iusmaterialismo o dejar abiertas las denominaciones y las fronteras a todas las variantes que confronten el saber jurídico hegemónico, o qué relaciones deben darse con otros juristas que se declaran defensores de derechos sin ser críticos del modelo normativo estatal. Estas preguntas además de políticamente pertinentes se constituyen como científicamente consistentes.

En su momento tuvo sentido preguntarse por su origen en América latina, si fue con la publicación de $E l$ derecho como obstáculo al cambio social (Novoa 1975) o la aparición

\footnotetext{
Académico Escuela de Derecho Universidad Academia de Humanismo Cristiano. Doctor en Derecho, Derechos Humanos e interculturalidad. Universidad Pablo de Olavide. Sevilla. España.rcalderon@academia.cl / rodrigocalderonster@gmail.com (ORCID: https://orcid. org/0000-0002-5459-7258).
} 
del primer número de El otro Derecho (1988), si fueron las acciones de los servicios legales alternativos o los límites de las defensas de derechos humanos contra las dictaduras de seguridad nacional o los jueces alternativos los que impulsaron a la teoría o fue al revés. Surgieron otras: si el jusnaturalismo podía coincidir con el materialismo jurídico; si con libros fundamentales como Estado, Derecho y Luchas Sociales (Santos. 1991) o Pluralismo Jurídico de Antonio Carlos Wolkmer ( 2001), o tras el encuentro con los ibéricos (Herrera, Sánchez) el derecho alternativo europeo encontró continuidad o si hay originalidad en el subcontinente americano. Estas cuestiones permiten apreciar una panorámica de la pluralidad de identidades de la Teoría Jurídica Crítica, pero también cómo el saber surge desde la lucha microfísica local hasta las reflexiones doctrinarias que apuntan a la lucha por los derechos y la satisfacción de las necesidades como centro. Por ello si se quiere repensar la vigencia y desafíos de las Teorías Críticas del Derecho en los nuevos contextos es necesario buscar los nodos de su red, revisar cómo latencias que se reponen en las luchas mantienen el movimiento; no solo historiografiando sino ganando textura, profundidad y recursividad al analizar.

\section{Genealogía, tensión, producción}

Las Teorías Críticas del Derecho como conjunto de prácticas forman parte de un campo en tensión con otras posiciones, fundamentos y prácticas que se hacen a sí mismas, pensadas en forma diferente a otras hegemónicas, un ejercicio en parte común en parte diferente, que aún compartiendo algunos métodos difieren en el punto de partida y de llegada con otras modalidades de defensa; se delimitan por diferenciación y afirmación de contenidos y objetivos, tienen una historia y una genealogía reconocible y mantienen en disputa su actualización en contextos de dominación que mutan; y persisten en la búsqueda de una efectividad de justicia material. Estrato construido por operadores que lo activan. Como escribió Fernando Rojas (1988): 
una generación de abogados ha trabajado duramente por disipar el estereotipo que se tiene sobre ellos. Ha intentado deshacer el ropaje que les hace ver elitistas, defensores del Estado y del estatus quo, y descorrer el velo que mitifica el derecho (p. 8);

prácticas señaladas por sus puntos cardinales: a) servicios legales alternativos y defensorías populares ${ }^{2}$, b) hermenéutica y resolución crítica por abogados litigantes y jueces que planteaban movilizar el derecho hacia soluciones que removieran los obstáculos que impedían la justicia material para los más débiles, desbancando en ello "el discurso jurídico oficial representante de la ideología liberal, capitalista y positivista de su condición de discurso único, metamorfaseado en ciencia neutra y apolítica" (De Carvalho y De Carvahlo. 2004. p. XI); c) reflexiones teóricas que atacan los supuestos del derecho liberal, formal, positivista, normativista y punitivista que sustenta las desigualdades sociales, que frente al agotamiento y a la crisis del actual paradigma de la ciencia jurídica tradicional (ya en sus vertientes idealista-metafísica , como en su vertiente foralpositivista) develan, lenta y progresivamente, el horizonte para el cambio y la reconstrucción de paradigmas modelados por contradiscursos crítico desmitificadores. (Wolkmer. 1994. p.14); d) una red de prácticas educativas y académicas que resumen, analizan, critican y recrean los límites de lo jurídico en una politización del hacer pedagógico; e) finalmente en el campo de los derechos humanos desde la llamada Teoría Crítica de los Derechos Humanos se sostiene que no basta el enunciado de derechos universales sino que es necesario reclamar derechos materiales, luchar por la eficacia de estos, enjuiciar críticamente los límites de esa forma abstracta de humanismo que prioriza el acceso al derecho judicial antes que a las condiciones materiales de vulneración, abstracción que olvida que "los valores de las fuerzas sociopolíticas la producción normativa, y sin embargos

2 Al respecto puede verse Jacques P. Manuel. Una concepción metodológica del uso alternativo del derecho. El otro Derecho N 1. Ilsa. 1988. 
estas manifestaciones de poder, de intereses y de valoraciones sociales parecen desaparecer del derecho positivo como producto final (Medici. 2011. p. 39).

Todas estas prácticas pueden ser consideradas un estrato. Deleuze y Guattari (2010) indican que son capas constituidas al "formar materias, en aprisionar intensidades o en fijar singularidades en sistemas de resonancia y de redundancia" (p. 48), máquinas de capturas de acciones molares que se conectan, que actúan por codificación y territorialización, que forman un plano de condensación entre dos capas, los sustratos. Aportan a la vez acciones, experiencias, densidades y movilidades en la medida que cambia su estabilidad por densificación o por movimiento (re)generativo. "Un estrato considerado en su unidad de composición solo existe, pues, en sus epistratos sustanciales que rompen su continuidad, que fragmentan su anillo y lo gradúan" (p. 57) de manera que a la vez que verifica su composición se generan puntos de ruptura, de territorialización y desterritorialización, líneas que guardan independencia recíproca "sin necesidad de tener en cuenta los órdenes de tamaños” (p. 65). Entre ellas se arrastra una ondulación, un recuerdo, una forma de construcción, densificación y reordenamiento que produce su movimiento y afianza una potencia; un juego que resulta sorpresivo mirado desde una instancia y desde otra parecer organizado y planificado; apariencia de repetición de la forma tradicional verifica una praxis diferente que las recrea.

Las Teorías Críticas del Derecho forman un estrato. Entre los puntos cardinales que las constituyen hay continuidades $\mathrm{y}$ diferencias, pluralidad y diversidad, programas de investigación y acciones locales, programa/acción que se territorializa en el conflicto concreto y desterritorializa en acciones dispersas que se reconocen, se aprenden, replican, analizan y reconstruyen solidariamente. Prácticas tipologizadas en conflictos reconocibles, que Jacques (1988) designaba como conflictos entre necesidades humanas insatisfechas y norma legal, procedimientos violatorios, decisiones de autoridad que ocurrentes en un lugar concreto su saber las extiende a un nivel abstracto que se 
conecta con ese punto de ruptura, pasando del sustrato de esa disputa de micropoder a la abstracción conceptual que condensa lo que está en disputa, que se vivifica en perseverar, un conatus $^{3}$ donde el derecho queda expresado como

ordenamiento jurídico debe ordenarse y referirse, a su vez, al sistema económico entendido como la forma de apropiación, concentración y distribución de los bienes y el sistema sociopolítico, entendido como el tejido organizacional y su relación con los niveles de distribución del poder (Jacques. 1988. p. 38).

Se trata ya no de la pregunta por la verdad de la norma sino por la decisión que debe resolverse el conflicto. "Se produce una laguna axiológica cuando existe una norma jurídica aplicable en el caso concreto, pero su aplicación a la situación específica conduce a una decisión injusta, es decir, una decisión que está en desacuerdo con los valores sociales" (Losano. 2004. p. 101); un juego de normas y valores que constituyen relaciones precisas de fuerza en un sistema social. Cuando se resuelve el conflicto satisfaciendo la necesidad insatisfecha y se ajusta la aplicación de las normas a ese objetivo los movimientos en los estratos se estabilizan, cuando por el contrario los niegan se licuefaccionan y el estrato se desplaza, remueve el sistema, da curso a un conflicto que se reactiva volviendo el sistema inestable. Es en el territorio donde se actualiza el desplazamiento, se aprende, se comparte la sistematización de prácticas y se construye teoría que conecta rizomáticamente sin pretensión de unificación sino de encuentro en ese movimiento múltiples y lo usa no para ordenarse jerarquícamente sino como referencia entre sus puntos cardinales. Por eso las Teorías Críticas del Derecho no son un orden sino una relación de ejercicios que dialogan, que se estratifican y mueven buscando fluidez; por ello no permanecen en el paradigma de la certeza sino en el de la pregunta. Esas praxis operan en tensión con otras prácticas con las que se reconocen semejantes pero no idénticas. Es esa

3 https://sites.google.com/site/diccionariodecenteno/c/conatus 
tensión lo que las hace un saber propio, plural y conectable con su objetivo axiológico de lucha por la dignidad humana y de satisfacción de necesidades.

Al decir de Bordieu (2011)

Los campos se presentan a la aprehensión sincrónica como espacios estructurados de posiciones (o de puestos) cuyas propiedades dependen de su posición en estos espacios, y que pueden ser analizadas independientemente de las características de sus ocupantes (que en parte están determinadas por las posiciones) (p. 112)

y en todo campo encontramos una lucha que debe ser estudiada en su especificidad por sus prácticas que constituyen un esquema generativo de estrategias "que pueden ser objetivamente conformes con los intereses objetivos de sus autores sin haber sido expresamente concebidas con ese fin" (p.119).

Esto nos permite situar los puntos cardinales de las teorías críticas en relación con sus contrapartes de modelos jurídicos formalistas y hegemónicos para comprender como las Teorías Críticas se construyen en esa doble acción de oposición y diferenciación. Mientras que el derecho hegemónico destaca por su matriz estatista, formalista y monista, en que "la formalización de la dogmática jurídica, resultante de datos lógicos y padrones de control jerarquizado inmunes a proposiciones y a juicios axiológicos, reduce el Derecho al orden vigente" (Wolkmer. 2006 p.69) las Teorías Críticas del Derecho proponen procesos cognitivos y de regulación plurales. Mientras el monismo jurídico encierra su juridicidad en la norma estatal y el conocimiento dogmático, "el pluralismo jurídico es la consecuencia metodológica de un empirismo radical, producido por los datos inmediatos y por la movilidad intensa de la experiencia jurídica" (Wolkmer. 2006. p. 176) y con ello de regulación de los espacios por sus habitantes directos, lo que da origen a la cohabitación de sentidos y prácticas.

Mientras el derecho formalizado busca la imponer soluciones de adecuación donde "la decisión está ya prevista en el 
sistema, salvo en casos excepcionales y que al intérprete no le corresponde un papel constitutivo, sino explicitador de algo ya dado, y por consiguiente, reducible a pautas cientifizadoras" (Saavedra. 1978. p. 45) las Teorías Críticas definen el derecho como juridicidad abierta en un criterio de primacía de la materialidad antes que solo declarativo; lo proponen como mecanismo de redistribución de poder y riqueza que mejore las vidas cotidianas efectivas. Mientras el formalismo apela a valores de orden, certeza y acatamiento de procesos lógico-racionales abstractos como hace Rawls (1995), las Teorías Criticas del Derecho proponen "una nueva perspectiva de los derechos como procesos institucionales y sociales que posibiliten la apertura y consolidación de espacios de lucha por la dignidad humana" (Herrera.2011 p.13).

Si por un lado la concepción privatista y procesalista liberal señala que los conflictos deben ser entendidos como individuales, patrimoniales, sujetos a mediación institucional, en que la defensa coincide con la de determinado grupo en posición dominante, las Teorías Críticas del Derecho plantean, como señaló Jacques (1988) una opción de disputa por los carenciados y necesitados en un horizonte de transformación social para la satisfacción de las necesidades, con métodos de trabajo que combinan acción institucional y social, que tiende a lo colectivo, en que la defensa no es solo profesional sino también comunitaria, con estrategias legales pero también jurídicas ampliadas a todas las esferas de discurso y acción, donde el valor de la participación en la demanda, en el proceso reivindicativo y en la construcción del resultado es central, que busca la amplia socialización de la comprensión jurídica y no el cierre al lenguaje de expertos. Frente a la norma como productor de certeza la Teoría Crítica del Derecho cree "inaplicables determinaciones de traslados mecánicos de sistemas globales normativos y de paquetes generales, absolutamente impuestos por un proyecto sociopolítico desde su estructura direccional" (Jacques. 1988. p. 32) y opta por un razonamiento que excluye la arbitrariedad y una justicia material antes que formal, que entiende la lucha 
por el derecho como un proceso de desarme del estado de abuso y cambio del estatus quo capaz para producir dignidad,

Entendiendo por dignidad, no el simple acceso a los bienes, sino que dicho acceso sea igualitario y no esté jerarquizado a priori por procesos de división del hacer que colocan a unos en ámbitos privilegiados a la hora de acceder a los bienes y a otros en situaciones de opresión y subordinación. (Herrera. 2011. p. 26).

La Teoría Crítica del Derecho rompe así con el sentido del derecho que apunta siempre al individuo y al orden, qué como sostuvo Hegel (1987) "esta identidad del ser en sí y el ser puesto solo tiene obligatoriedad como derecho lo que existe como ley" (p. 331) en que el conflicto se resuelve aislándolo del contexto, burocratizando y ratificando el momento original del orden legal. Contra esto se propone introducir marcos de realidad en el debate, colectivizar y contextualizar el problema, promover la participación, manifestar un razonamiento de alteridad material y provocar satisfacción de necesidades y protección continua y no solo garantizar orden. Como sostiene Diego Duquelsky (2018)

La visión que sostienen las teorías críticas sobre la cuestión hermenéutica y la actividad judicial va a estar íntimamente ligada a su caracterización del derecho que, en palabras de Carlos Cárcova puede ser entendido: como una práctica social específica que expresa y condensa los niveles de conflicto social, en una formación histórica determinada. Esa práctica es de naturaleza discursiva, en el sentido que la lingüística atribuye a esta expresión, esto es, como proceso social de producción de sentidos (Cárcova, 2001: 30). El discurso al que nos estamos refiriendo, abarca tanto el de la ciencia del derecho, como el de las autoridades y los súbditos. Lo que los magistrados establecen, lo que los legisladores sancionan, lo que los abogados argumentan, lo que los litigantes declaran. Y no queda en las palabras. Esta práctica representativa incluye actos, gestos, ritos, creencias, mitos y ficciones. (p.196) 
Con esa confrontación es que se verifica lo que Bordieu (2011) caracteriza como propio de la actividad en un campo determinado: la producción de un discurso ajustado a una situación y de un habitus que debe señalarse como "una especie de máquina transformadora que hace que reproduzcamos las condiciones sociales de nuestra propia producción" (p.133); en esa tensión se reconstruyen los procesos de conocimiento y comprensión del derecho. Ese discurso que se recrea en prácticas de disputa encuentra a su vez un eco en la academia que ya no solo enseña lo jurídico como un sistema normativo sino como un sistema de estrategias jurídicas en que el cuerpo de normas y procedimientos no resuelven por sí los conflictos sino que se trata de hacer un derecho "que contribuye a la creación y la prevención de disputas, así como a su solución mediante un discurso argumentativo acompañado de la amenaza de la fuerza" (Santos. 1998. p. 20), que al romper con la sacralidad de la perspectiva estatal lo define como un fenómeno social y político y hace posible la pluralidad que se opone a la abstracción monista. Se retoma así la idea del derecho como debate por la justicia y saber que construye analogía, hermenéutica, estándares de aplicación y mecanismos para medir esa justicia en tanto "el derecho tiene como finalidad la obtención de la justicia, principio inspirador que orienta el respeto integral del ser humano" (Sánchez, Seco, Suárez. 2005. p. 17).

\section{Una teoría iusmaterial posible}

Hace unos años (Calderón. 2013) sostuvimos que la Teoría Crítica del Derecho operaba sobre una red de matrices teóricas comunes en su diversidad. Hoy creemos posible ratificar que este campo posee un objeto propio de saber/hacer. Frente al derecho formalista fenomenológicamente aislado del contexto natural y social la Crítica Jurídica replanteó ese horizonte epistemológico abriendo sus fronteras a procesos e implicancias sociales buscando serr una disciplina dialogante, una ciencia del derecho pluralista e impura. Similar cuestión hizo con la 
relación derecho y política, esferas que "no pueden separarse en la consideración de nadie puesto que son lo mismo: la forma y la sustancia del único proceso real de desenvolvimiento de una sociedad" (Barcellona. Coturri. 1976. p.13) y develó el rol instrumental del derecho formal como base de garantía del orden social dado. Al mostrar ese ocultamiento rescató el rol de las comunidades así como el aspecto positivo del poder de éstas al plantear su redistribución recuperando el pluralismo.

Si deja de entenderse que los sujetos sólo tienen aquellas facultades que se encuentran en la ley y se busca el derecho en la materialidad esto implica un cambio de saber y de metodologías. La pregunta clave ya no es por la fuente formal sino "la idea de un derecho como medio ordenado a la satisfacción de las necesidades fundamentales del Hombre. Por lo cual lo jurídico sobrepasa lo legal" (Jacques.1989.p.2). Se trata de una inversión de los criterios de la actividad jurídica desde la propiedad sobre los bienes protegidos hacia las necesidades humanas; con ello las relaciones entre sujetos dejan de entenderse como exclusivamente económicas para ser sociales, relaciones complejas individuos/comunidad sin que el entorno sea solo objeto de apropiación y consumo. Por tanto si cambia el criterio de la relación jurídica debe cambiar también el de la justicia, si no es ya el de la ley donde la formalidad y abstracción borra las diferencias de capacidad entre los sujetos reales lo justo requiere otros estándares de medición. La justicia necesita forma pero también medida material que permita observar y verificar un cambio efectivo en la situación que origina la conflictividad; la resolución del conflicto requiere discutir la disposición de los elementos que determinan la posición inicial de cada parte a fin no solo de reordenar la situación sino de redistribuir los elementos que obstaculizan la satisfacción de esas necesidades y causan el conflicto; con ello deben cambiar además los sujetos protagonistas, ya no individuos abstractos sino actores materialmente existentes en sus circunstancias, por lo que producir justicia implica discernir entre alternativas que afectan a implicados reales de manera efectiva, remover condiciones 
materiales o culturalidades opresoras, así como debatir sobre la conveniencia de aplicar la ley y de qué forma hacerlo. Como señalaba Alda Facio (1992) una ley debe analizarse y reconocerse como discriminatoria no tanto por su contenido sino por su resultado.

En ese debate la crítica jurídica replanteó un asunto clásico de derecho procesal, el del conflicto: la litis procesal no responde a todos los conflictos sociales y restringe a una esfera de adecuación normativa y no material y multidimensional las relaciones sociales. Mientras que en la concepción positivista del derecho el conflicto se da siempre entre particulares con intereses contrapuestos y supuesta igualdad de condiciones, ya que por ideología se "parte del falso supuesto que la sociedad se encuentra en estado armónico, por lo cual de hecho se protege el status-quo, o sea, la posición socioeconómica ventajosa de un grupo sobre otro" (Jacques. 1986. P.14) el conflicto jurídico material no se reduce a clasificaciones disciplinares rígidas (derecho civil, penal, laboral, etc.) sino que se visualiza como una relación de actores en los diversos planos en que existe insatisfacción de las necesidades humanas y violación de Derechos Humanos; el litigio es así solo un momento de ese conocimiento. Las prácticas alternativas del derecho ponen en discusión el hecho que la institucionalidad pretende separar juridicidad de orden político, cuando sabemos que incluso los conflictos sociales individuales como el sexismo o racismo son manifestación de conflictos colectivos. "Visualizada así esta concepción abierta a la sociedad real, el conflicto jurídico no solamente se establecerá con la estructura jurídico institucional, sino también con las estructuras económicas, políticas y sociales" (Jacques. 1996.p 15).

Si todo conflicto jurídico es un conflicto ampliado, intersubjetivo no solo de intereses sino esencialmente de necesidades insatisfechas, usar el derecho no necesariamente es judicializar un conflicto: "Los usos del Derecho varían dependiendo tanto de la realidad -análoga - Derecho que se utilice, como de quién haga precisamente esa utilización" (De la Torre. 1990. p. 10). Si 
el derecho es una práctica localizada de tácticas y estrategias que ocurren en una geopolítica determinada sus aplicaciones nunca son neutrales. El derecho puede ser usado también contra el orden dominante, haciendo de él una herramienta de lucha por la demanda o defensa de los necesidades económicas, políticas y sociales de la sociedad civil, un instrumento "que reconozca efectivamente los derechos de la población, sus prácticas culturales y sociales recobrando su naturaleza estrictamente universalística, no instrumental al servicio del poder y de la política de los sectores económicamente dominantes" (Rodríguez. 1990. p.65).

Resignificar los usos del derecho necesariamente lleva a determinar quiénes son los sujetos del uso del derecho. La Crítica Jurídica amplia los horizontes profesionalizantes de la abogacía como forma no participativa de ejercicio del poder. "Estos espacios que los abogados llenan como tales, "profesionalmente", son espacios políticos; que reclaman la actitud política del abogado profesional." (Correas. 1985.p. 218), En la estrategia de defensa tradicional la representación del caso señala como actores a los abogados y el Poder Judicial; en una estrategia jurídica ampliada no solo se trata de defensa litigante sino que instalado el conflicto en lo social se requieren acciones que incluyen a los afectados, especialmente si se trata de colectivos y comunidades. Frente a un fenómeno colectivo no puede tratarse al grupo solo como un agregado de individuos, lo que desnaturaliza su estado, sino que se requiere un reconocer que comprenda además de defensa judicial otras prácticas conjuntas de defensa, movilización, educación, afirmación de auto organización, crítica y denuncia del sistema legal, acciones que promueven la reapropiación de lo jurídico por los actores sociales.

Si la Teoría Crítica del Derecho se constituye en la pluralidad teórica, práctica, argumentativa y subjetiva que se conjugan en apertura hacia los contextos, ello deviene en una teoría impura del derecho, una matriz que considera primero el cuestionamiento de la objetividad de los ordenamientos jurídicos 
y la neutralidad de los jueces; que cuestiona el razonamiento jurídico en tanto justificación del orden; que realiza operaciones que rompen el cerco disciplinar; que denuncia activamente el legalismo que se vincula con la dominación material y simbólica de la lógica contractual; que desarrolla estrategias que desafían las formas políticas de producción y protección del capital; que se constituye en un discurso de retórica propia distinta al formalismo normativista; que deconstruye el conocimiento jurídico, recompone sus elementos y se vincula a otros saberes. De ésta forma una matriz de saber fundada en la Teoría Crítica del Derecho, pluralista, finalista y materialista del derecho puede plantearse de la siguiente forma:

1. El derecho en tanto dice relación con el fundamento y ejercicio del poder, con la producción de sus formas y las relaciones entre los sujetos debe tender a la producción de una subjetividad emancipada, cuyo ejercicio nunca es neutro sino una disposición estratégica de elementos.

2. El derecho es una práctica social en la medida que se ejerce y activa estrategias y despliegues tácticos que impactan más allá del caso particular. Por eso "No basta con proclamar derechos, aunque ello sea esencial. Hay que crear además un entorno que favorezca el ejercicio real de sus derechos por las propias poblaciones". (Juristes Solidarités. 1993.p. 8)

3.- El derecho crítico es un discurso disciplinar en la medida que se singulariza a sí mismo como jurídico. Si como decía Foucault (1982) el discurso "es ese conjunto regular de hechos lingüísticos en determinado nivel, y polémicos y estratégicos en otro" el que un debate sea o no jurídico es una lucha de posiciones. La dogmática jurídica pretendió un discurso cerrado y definitivo sobre los textos normativos, olvidando que "en el discurso jurídico se juega la correlación de fuerzas entre las fracciones en lucha por el poder", (Correas. 1995. p. 80) por lo que producir discursos diferentes implica significados para una nueva cultura de derechos y vinculaciones e-co-responsables. 
4. El derecho hace una práctica de su propio discurso, despliega tópicos discursivos presentes en los espacios sociales y políticos en que actúan los sujetos y consiguen así producción de su subjetividad en nuevos escenarios de resolución de conflictos y de disputa por las categorías de lo justo y necesario. Ese ejercicio de uso afirma lo diferente y operacionaliza nuevas estrategias de resistencia y de conquistas.

5. El derecho tiene lugar tanto en el estado como en la sociedad civil. El pluralismo jurídico mostró como en un mismo espacio geopolítico coexisten órdenes normativos diversos, funcionales o que confrontan la legalidad del Estado. Por lo tanto restringir lo jurídico al estado es restringir el horizonte de posibilidades de uso y apropiación de los derechos.

Contrariamente al insuficiente paradigma estatal dominante, representado por el dogmatismo jurídico convencional, el Derecho Comunitario, por estar inserto en prácticas sociales plurales, de las cuales es producto, trasciende a los órganos estatales, emergiendo de varios y diversos centros de producción normativa y adquiriendo un carácter múltiple y heterogéneo. (Wolkmer. 1994. p. XVI)

6. El sujeto jurídico es plural, admite sujetos individuales, colectivos y comunidades. En la cultura jurídica liberalburguesa la categoría sujeto ha sido falseada, se describe la actividad del propietario como modelo único de subjetividad, por ello la actividad de comunidades y colectivos no encuentra respuesta apropiada. Se oculta así que el sujeto puede ser construido "desde una estructura simbólica transindividual, desde el Otro, que define y ubica al sujeto en un sitio de esa secuencia significante, discursiva" (Braunstein, 1987. p.108) y potenciarse en una totalidad comprensiva de la multiplicidad de esferas del individuo.

7. Las prácticas jurídicas se desarrollan tanto en espacios institucionales, comunitarios como personales. Si el derecho se libera de la exclusividad estatal y los sujetos adquieren carácter plural ello trae como consecuencia la ampliación 
de los espacios donde se verifican prácticas jurídicas; así las prácticas individuales adquieren politicidad y juridicidad finisecular y las colectivas una unidad de subjetividad compartida e integradora.

8. Los fines y funciones del derecho son siempre definidos desde lo político. Si el derecho tiene que ver con el poder no es una herramienta al servicio de cualquier política como imaginó Kelsen, sino que en verdad el derecho es la expresión formal de la política misma. Cada estrategia formula su propio sistema de derecho, funcional a sus objetivos.

9. La pluralidad es la base de todo otro hacer juridicidad. No se trata de diversidad dentro de una misma matriz sino de construcciones diferentes que armonizan y concatenan en un despliegue de posiciones, disposiciones, intereses y fines. Construir proyectos jurídicos de promoción y producción -no solo aceptación - de la pluralidad requiere romper con un pilar fundamental del llamado Estado de Derecho: no hay verdadera comunidad jurídica en tanto el eje de los derechos sea la ley; el paso siguiente de una nueva juridicidad es la igualdad, desigualdad y distancia entre estos polos puestos en contexto multidimensional, afirmados sobre la materialidad de las relaciones sociales y jurídicas y orientada a la satisfacción de necesidades por redistribución del poder social.

\section{Confrontar los ciclos políticos y económicos}

Intentaremos ahora responder dos preguntas que nos parecen cruciales para la Teoría Jurídica Crítica, las de su vigencia y su potencia. Para ello es necesario revisar someramente las coyunturas históricas en que surgió y desarrolló, incluyendo los ciclos progresistas y el momento global neoliberal desintegrador y neofascista del siglo XXI.

Si en Europa hasta la década de 1960 la crítica consistía en una reacción al capitalismo y al modelo liberal autoritario de estado (Poulantazas, Mialle) y con posterioridad a Mayo del 
68 a la alienación del individuo "es captado por numerosos dispositivos de control y se hace cada vez más extraño a un trabajo reducido a la repetición cadenciosa y embrutecedora de gestos mínimos, (Gobille. 2018) la escuela del Uso Alternativo del Derecho en Italia y España se planteó el uso de los dispositivos judiciales posibles para usar como dispositivos de emancipación. En América Latina el contexto original fue la reacción a las masivas violaciones de derechos civiles, políticos, económicos, sociales y culturales que las dictaduras de seguridad nacional realizaron para instaurar regímenes neoliberales. Los juristas democráticos las confrontaron con el arsenal legal tradicional hasta verse frente a una constatación: el derecho al ser usado como instrumento de defensa o liberación choca con su límite de ser instrumento del orden y con ello herramienta de dominación; por eso la urgencia de actuar con un sentido militante de guerrilla jurídica urgente. De allí nacen las preguntas fundamentales de la Teoría Crítica del Derecho.

Tras la década de los ochenta del siglo veinte la oleada democratizadora trajo nuevos contextos de relativa apertura política, en que la violación de derechos se producía en contexto de estados formalmente democráticos y políticas económicas libremercadistas. Las nuevas políticas públicas neoliberales consistentes en el retiro del Estado del control soberano de su territorio y sus comunidades, con persistente desregulación laboral, no fiscalización de los aparatos financieros, políticas económica y socialmente regresivas mostraron que el neoliberalismo era no solo un modelo económico sino un proyecto político profundo y un inédito proceso cultural de sustitución de soberanía jurídica proteccionista por una economía auto regulada, una lógica del consumo como patrón de integración social y una teoría política que sustituye al ciudadano por el consumidor.

Al decir de José Eduardo Faría (1995) los rasgos más importantes son los siguientes:

a) Crecimiento con desempleo, restringiéndose el mercado de trabajo por su traslado a países con menores salarios y protección laboral. 
b) Heterogeneización de las relaciones laborales de acuerdo a su grado de calificación.

c) Desempleo estructural y xenofobia, ya que ese desempleo estructural aumenta la violencia contra los extranjeros inmigrantes.

d) Fragilidad sindical, ya que la reivindicación de derechos laborales se sostiene lleva a disminuir la competitividad de las empresas.

e) Deterioro de las condiciones de vida: la privatización de los servicios esenciales encarece su costo, que los desempleados no pueden pagar, marginalizándolos y haciendo aumentar la violencia urbana.

f) Concentración de la renta, ya que el proceso económico de la globalización favorece la apropiación y concentración de los ingresos, conocimientos y derechos, disminuyendo el haber de los sectores sociales más pobres. (p. 30-31)

A lo que se sumaron otros tres fenómenos complementarios: i) Una crisis del Estado y del derecho como articulador social, reemplazándose por los criterios de la lex mercatoria; ii) una divergencia entre los tiempos de las urgencias sociales y las decisiones tecno burocráticas del estado; iii) La fragmentación del ejercicio del poder en una multiplicidad de centros de decisión y de producción de la dominación material y simbólica.

Las luchas sociales debieron enfrentar tanto la acción/omisión del Estado como los escenarios creados por los sectores privados que usan esta forma de Neo(No)Estado. Si antes la lucha de los movimientos sociales y de la crítica jurídica fue por el uso del derecho en beneficio de las mayorías explotadas y las luchas de resistencia los métodos debieron adaptarse a las formas de participación en procesos políticos semi abiertos buscando constituir "sujetos individuales y colectivos con poder de acción y decisión, capaces, en pleno gozo de la ciudadanía, de ejercer el control democrático sobre el Estado o sobre otra cualquiera forma de poder instituido" (Wolkmer. 1994. P.227), y así resistir y combatir la alianza bajo este nuevo modelo de 
capital y estado. Se encuentra pendiente hacer estudios relevantes sobre el comportamiento de la Teoría Crítica del Derecho y las prácticas jurídicas populares bajo el llamado "Ciclo Progresista” inaugurado por la elección de Chávez en 1998, y sus repercusiones:

hubo una recuperación del papel del Estado en la economía, se desplegaron políticas sociales que redundaron en una reducción de la pobreza, en números absolutos y porcentajes. En varios países hubo mejoras en el terreno laboral que resultaron en aumentos de los salarios reales (incluso del salario mínimo), volvió a crecer el mercado formal de trabajo, se fortaleció la negociación colectiva y la actividad sindical, en algunos casos se llegó a niveles cercanos al pleno empleo, hubo recuperación de la economía campesina con apoyo de políticas públicas. (Codas. 2015. p.2)

Se verificó así una convivencia entre elementos de la globalización neoliberal con mejoras salariales y sociales, fortalecimiento de la actividad estatal y la incorporación al aparato público de importantes actores que habían sido militantes -jurídicos o políticos- contra el modelo neoliberal. Aún no sabemos con certeza si en ese proceso se verificó una relativa tregua de los movimientos jurídico-populares con las fuerzas en el estado, una alianza, una subsunción en ella y/o si operaron desde fuera colaborando más o menos críticamente con estos gobiernos. Sin estudios de respaldo es nuestra impresión que algunos actores importantes, como el MST en Brasil, asumieron una colaboración crítica, en tanto otros se subsumieron en las instancias formales del estado, apelaron a expandir el horizonte legislativo o judicial y coparon defensorías estatales, lo que se tradujo en un reforzamiento de las prácticas formalistas que antes se criticaban. Hay aquí un completo programa de investigación por hacer.

Sabemos además que éste ciclo político trajo lo que se ha denominado como neo constitucionalismo latinoamericano, que comprende los procesos que van desde la Constitución 
Brasileña de 1988 hasta la Constitución Boliviana de 2009. Como muestra Medici (2016) implicó un desplazamiento del debate hacia la institucionalidad, entre seguir la teoría constitucionalista liberal enseñada en las universidades, que "se presenta desde el principio como teoría y práctica del gobierno limitado (p.169) y lo que este mismo autor establece en cuanto a que "los procesos constituyentes impulsados por la movilización popular de los grupos subalternizados en Venezuela, Bolivia y Ecuador nos está mostrando la necesidad de replantear el concepto mismo de poder constituyente" (p.182), que implica reconocer un genuino pluralismo e interculturalidad que lleve a una redistribución del poder hacia esos grupos. Con estas nuevas constituciones se abrió "el espacio de confrontación entre los derechos de los miembros de la comunidad política, y las instituciones constituidas positiva y concretamente" (p.191), donde nuevamente se plasma la tensión de los derechos consagrados como lucha por acceder a los bienes que permiten vivir.

La recuperación crítica del punto constitucional donde se articula una imagen social, una narración sobre el pasado, el presente y el proyecto, la necesidad de consistencia de la justicia social desde la articulación de lo ecológico, lo económico y lo político, el reconocimiento de la pluralidad social, de nuevos derechos humanos y garantías sociales, políticas, jurídicos, son objeticos irrenunciables de la sociopraxis crítica que no hay que abandonar a la ofensiva de los globalizadores hegemónicos, ni de sus aliados los constitucionalistas conservadores y encriptadores. (Medici. 2016. p. 354).

Ese avance de garantías y derechos por un lado corre el peligro de volver al pensamiento emancipador en pensamiento formal, tornar más importante lo escrito que el sentido, donde juristas formados en el formalismo normativista se extravían entre la forma y la axiología. Esto a su vez choca con las nuevas fases del neoliberalismo global reforzada desde Trump en adelante, que significó que la derecha pusiere fin a ese ciclo ganando las elecciones en casi todos los países, 
En el nuevo ciclo post-progresista, se ha retomado el camino neoliberal (como en Argentina y Brasil); hay condena política a los antiguos gobernantes contra quienes se arguyen procesos judiciales (Cristina Fernández, Dilma Rousseff o Lula); se denigra o desvaloriza todo lo que se logró en el pasado inmediato; se encuentra apoyo en las fuerzas más tradicionales y reaccionarias, que fueron ejes de la oposición; se abandona el latinoamericanismo; se hace uso de la persecución política y se aprovechan los escándalos de corrupción para levantar los ánimos ciudadanos. (Paz y Miño. 2017)

Para poder contestar las preguntas actuales de la Teoría Crítica del Derecho debemos caracterizar el neoliberalismo actual que podemos designar como global, desintegrador y de post estado nacional, en que la acción del capital es cada vez más global, totalitaria y desenfrenada, buscando subsumir no solo la producción de bienes y de valores sino la vida entera.

Porque el capitalismo busca ahora expropiar el plusvalor no solo del trabajo en sentido estricto, sino también del ocio; ni solo de la propiedad privada, sino también de lo que los autonomistas llaman el común, y no solo de las cosas palpables, sino también de los sentimientos y los ánimos y los estados subjetivos. Todo debe ser comercializado y sujeto a competencia. Todo debe ser identificado como una marca. (Shaviro. 217.p. 172)

El estado nacional que conocimos, basado en una soberanía que se fundaba en el control de recursos, poblaciones y fronteras está siendo horadado por arriba y por abajo. En la medida que los recursos que generan valor y riqueza son las transacciones inmateriales y financieras más que los naturales, éstos bienes deben extraerse a escala cada vez mayor y ofrecerse más allá de cualquier frontera y esto debilita la función estatal de control, que queda dirigida solo a las poblaciones. De la misma manera se ha erosionado por abajo el control jurídico y el sentido de protección de la sociedad. "El modelo geopolítico basado en el estado nación, ya no puede explicar 
el funcionamiento cotidiano de la vida. Hace falta un nuevo modelo de interpretación, basado en la transformación digital y la tecnología" (Berardi. 2019. p. 133)

Con ello el rol del estado ha cambiado. Srnicek y Williams (2018) indican que "el neoliberalismo difiere del liberalismo clásico por atribuir un papel significativo al Estado. Por tanto, una labor importante del neoliberalismo ha sido tomar el control del Estado y reorientarlo" (p.79) para regenarar permanentemente el espacio del mercado; la actividad del Estado se dirige a crear mercados, destruir los que no sirven y recrear a escala global y financiera lo que sea funcional a esto. Por ello en esta reconfiguración el estado es básicamente policía territorializada, y un hacedor activo de más mercado, donde el poder económico "demanda que el estado defienda los derechos de propiedad, haga cumplir los contratos, imponga leyes antimonopólicas, reprima la inconformidad social y mantenga la estabilidad de los precios a toda costa" (p.80). Ya no importa el derecho sino las reglas del juego.

El rol del mercado también ha cambiado, ya no es el lugar de intercambio ni el espacio económico regulado de producción de la riqueza sino un campo entre lo real y lo que creemos real (mercados a futuro, $\mathrm{i}+\mathrm{d}$, especulación algorítmica). "El mercado es una máquina de conciliación de esos dos planos" (Mason. 2016. p. 87), un espacio de técnicas para usar todo en la producción de más valor extraíble y apropiable. Lo que entendimos era el neoliberalismo en tanto técnicas monetarias y fiscales de deslocalización y privatización no era el modelo mismo sino instrumentos para destruir el sujeto enemigo del capital, el trabajo, e instalar su nueva antropología donde el Homo aeconómicus es diferente del sujeto propietario hegeliano. El juego ya no es voluntad y propiedad sino de intercambio y movilidad. El sujeto vende y consume y con ello gana y produce otras ganancias coetáneas, intercambia su propiedad como la ajena que usa (el espacio concesionado de las telecomunicaciones es el mejor ejemplo), ejercita y desea: "Existir es desear, y por consecuencia activarse" (Lordon. 2015.p.23). El derecho de propiedad solo es 
útil en tanto entra al juego de posesión y desposesión para el uso de las cosas en beneficio privado. Si tradicionalmente "El individuo estaría alienado cuando es separado de su potencia de actuar y reunirse con ella, volver a coincidir con ella sería el sentido último de la desalienación" (p.157) el nuevo sentido de la inclusión de los sectores sociales ya no es por el acceso y propiedad sino que son sujetos solo en tanto acceden a los campos, instrumentos y reglas de juego de la verdadera neoburguesía. El problema es de acceso y de uso no solo de tenencia o propiedad. Las tecnologías provocan cambios veloces y brutales y desde la apariencia de uso reformulan lo que debe entenderse por conocimiento y contenido de este uso.

El gobierno de la subjetividad también ha cambiado, ya no se trata solo de vigilancia, control o posicionamiento en lugares cognoscibles y aprehensibles sino que el asunto es el de las formas mismas de gobierno, ya no solo de gubernamentalidad como lo que planteó Foucault, "La impotencia de la subjetividad es un efecto de la potencia total que adquiere el poder al independizarse de la voluntad, la decisión y el gobierno de los humanos, merced a su inscripción en la textura automatizada de la técnica y el lenguaje" (Berardi.2019.p.31). En ese ejercicio la Lex Mercatoria se ha redefinido, reforzado y reorganizado global y finisecularmente hasta imponerse como sentido común y con ello el derecho corre el riesgo de volverse espejismo o ser solo la legitimación de forma de la eficacia de la fuerza de la represión o del mercado y esto es definitivamente un problema político.

\section{Vigencia y potencia de la teoría crítica del derecho}

Intentaremos responder las preguntas de origen de éste texto no en abstracto sino considerando el actual neoliberalismo global desintegrador y sus territorializaciones locales.

Las Teorías Críticas del Derecho nacieron de preguntas urgentes frente a opresiones históricas concretas y a partir de allí desarrollaron una metodología en espiral basada en esos interrogantes que eran desafíos: ¿cómo enfrentar las contradicciones 
entre realidad y legalidad mediante una acción distinta al hacer tradicional, como interpelar esa legalidad, que discursos construir, que miradas diferentes introducir apara ampliar los límites de la ciencia jurídica, como elaborar principios, objetivos y teorías propias, diferentes al saber oficial, para retornar al contexto material y la urgencia de la injusticia cotidiana? La producción de conocimiento y saber es siempre una cuestión metodológica, de manera que ese ejercicio de hacer/saber/hacer en las Teorías Críticas del Derecho no se plantea con pretensión de pureza ni verdad sino en perspectiva de apertura cognitiva y práctica.

A nuestro entender la Teoría Crítica del Derecho sigue vigente en su objetivo de buscar metodologías para hacer efectivos materialmente los derechos. Promover, educar y empoderar en los derechos a los sujetos plurales sigue siendo una necesidad por el contexto de carencia, alienación y subsunción de lo real en las formas mercado; pero sobre todo porque nos enfrentamos a problemas de regulación/desregulación que han mudado en su forma pero siguen provocando acumulación y exclusión de acceso y ejercicio de derechos. Igual que antes es necesario pensar y elaborar mecanismos que afirmen valores, principios, practicas y objetivos jurídicos que combatan el formalismo normativista devenido en mera regla de juego, que vaya más allá del solo activismo judicial recreando prácticas de lucha por la concretización material de los derechos y no se conforme en lo declarativo; y que obtenga de todo eso un conocimiento en sus diversos puntos cardinales, estratos y campos capaz de desplegar un saber comprensivo de lo institucional, lo material y sus intersticios e intervalos microfísicos y rizomáticos.

La siguiente pregunta que cabe es la de si las Teorías Críticas del Derecho tienen futuro. Para ello la interrogante se abre en una doble conjunción: primero si tiene sentido insistir en los derechos frente a los nuevos procesos globales y segundo cuales son las condiciones de posibilidad para realizarlos y adquirir eficacia jurídica, porque sin ellos como objetivos no hay crítica jurídica. La primera de ellas se vuelve tautológica porque la insistencia es una necesidad justificada en tanto los operadores 
jurídicos críticos se plantean como necesario develar la opacidad del orden hegemónico para abrir y visibilizar espacios de conquista de derechos, pero además por que la insistencia es un acto de voluntad afirmativa, toda vez que todo saber implica la disputa de poder.

Respecto de la condición de posibilidad esto nos lleva a revisar otras dos cuestiones: primero, cuál de las características, métodos y principios que las Teorías Críticas del Derecho proponen siguen siendo válidas en este contexto y al respecto podemos decir lo siguiente:

1. El pluralismo de acciones, métodos, perspectivas teóricas, sujetos y estatutos jurídicos es un axioma a mantener frente a la tendencia centralizadora, acumuladora y excluyente de las perspectivas monistas que refuerzan el no poder del derecho profundo frente al mercado.

2. Las acciones de defensa jurídica deben seguir planteándose como ejercicio de diferencias con las defensas legales tradicionales, toda vez que una defensa jurídica transformadora incorpora esos métodos tradicionales pero es consciente de sus limitaciones y trampas.

3. La perspectiva que el formalismo normativista encierra una tensión entre control de orden y emancipación debe tenerse siempre a la vista, de manera que el uso alternativo del derecho debe considerar ese punto de regreso al orden que es parte de lo que se disputa.

4. Que los operadores jurídicos deben ser también plurales, no solo juristas, ya que los actores en conflicto aportan desde su saber no formalizado riqueza metodológica y estrategias extra jurisdiccionales. Por lo mismo crear, fortalecer y desarrollar sujetos individuales, colectivos y comunitarios que luchen por sus derechos refuerza los principios anteriores;

5. Que toda teoría y práctica jurídico crítica que se proponga debe desafiar los límites y sentidos del orden patriarcal y liberal de lo jurídico y la desregulación neoliberal; y 
6. Que la perspectiva finalista y materialista de toda acción de defensa, interpretación o teorización del derecho debe encontrar su medida y posibilidad en la satisfacción efectiva de las necesidades humanas en una perspectiva no capitalista, es decir no sujeta a satisfacción solo de manera fetichizada.

La segunda cuestión es sobre que pistas podemos actuar en el contexto actual que describimos:

a) Frente a la acción global y descentralizada del capital las Teorías Críticas del Derecho deben proponer multiplicidad de acciones en planos diversos que se reúnan por sus objetivos y no por su referencia al ente estatal. Si en la interpretación neoconstitucinalista se plantea la internacionalización del derecho interno y la nacionalización del derecho internacional, hay que avanzar a pensar principios replicables en cada escala, en sus bordes pero también de los espacios intermedios de esos campos de manera que la tensión en ellos permita que los estratos se muevan y encuentren acomodos de derechos y necesidades.

b) Frente a la debilidad del estado nacional hay que fortalecer la perspectiva de uso emancipador del derecho no abandonando la disputa en la institucionalidad, toda vez que la desregulación busca precisamente eso, que dejen de usarse los espacios jurídicos y se recurra a los de resolución tecno-económica.

c) De esta manera más que reclamar una protección total del estado deben buscarse estrategias que irrumpan en los conflictos quebrando la lógica de desprotección y desregulación y que en esa irrupción disputen en qué sentido debe usarse el derecho y lo institucional buscando un reordenamiento de las relaciones sociales protegiendo al más débil.

d) Ante el rol del mercado como nuevo regulador del espacio político vaciado derechos hay que llevar esta disputa a su interior y proponen razón jurídica y no tecno financieras. 
Las experiencias en materia de intervenir y controlar proyectos financiados por instancias internacionales puede ser usada como base de reflexión/acción. ${ }^{4}$

e) La insistencia en señalar que el sujeto debe constituirse como sujeto jurídico de necesidad y solidaridad se vuelve un axioma. Combatir la antropología neoliberal del omo aeconómicos por el de sujeto de derechos es fundamental.

f) La producción de una nueva subjetividad en época de modelos parciales de regulación/desregulación abre puertas a una nueva subjetivación en épocas de cambio sistémico. Si hasta ahora subjetividad y derecho tuvieron que ver con lo gobernable ahora hay que pensar su uso tecnológico como acto de independizarse de los perímetros represores del estado pero exigiendo la concurrencia de ese estrato en una perspectiva no ideologizada en la soberanía parcelada del espacio nacional.

Esto que puede parecer insuficiente se relativiza si recordamos que estamos en un proceso de reordenamiento del orden global, medio y local y que la reorganización permanente es una característica de este orden global territorializado/desterritorializado - regulado/desregulado. Cuando todo se encuentra en movimiento tiene sentido actuar con la racionalidad, discursos y prácticas jurídicas centradas en los derechos para irrumpir en los momentos de esa reorganización continua, recordando que el derecho es un interventor de realidades que puede ser aislante o impulsado por prácticas de conectivas. En derecho es un tecno lenguaje que se ejercita en el modo múltiple de sus aplicaciones. Será esa insistencia la que dará respuesta a los límites futuros de la crítica jurídica. Crear un futuro donde no siempre se ve es lo que constituye la potencia de la voluntad crítica.

\footnotetext{
4 Al respecto puede verse Derecho a exigir respuestas. Reclamos de la Sociedad Civil ante el panel de inspección del Banco Mundial. 2005.
} 


\section{Bibliografía}

Barcellona, Pietro y Coturri, Giusepe. El Estado y Los Juristas. Editorial Fontanella S.A. Madrid. 1976.

Berardi, Franco. Futurabilidad. Caja Negra Editora. Buenos Aires. 2019.

Bordieu, Pierre. Algunas propiedades de los campos. En Cuestiones de Sociología. Akal / Itsmo. Madrid. 2011.

Braunstein, Nestor. Psiquiatría, teoría del sujeto, psicoanálisis. Editorial Siglo XXI. México. 1987.

Calderón, Rodrigo. Pensar otro derecho. Para una nueva poiética jurídica. Tesis Doctoral. Universidad Pablo de Olavide. 2013.

Clarck, Dana. Fox, Jonathan. Treakle, Kay. Compiladores. Derecho a exigir respuestas. Reclamos de la Sociedad Civil ante el panel de inspección del Banco Mundial. Siglo XXI Editores. Buenos Aires. 2005.

Codas, Gustavo. Desafíos al ciclo progresista en América Latina. Mate Amargo. Uruguay. https://www.mateamargo.org.uy/ 2015/08/13/desafios-al-ciclo-progresista-en-america-latina/ 2015.

Correas, Oscar. Introducción a la Sociología Jurídica. Editorial María Jesús Bosch. Barcelona. 1995.

Correas, Oscar. La democracia y las tareas de los abogados en América Latina. ILSA. Bogotá. 1985.

De Carvahlo Amilton y De Carvhalo Salo. Direito alternativo Brasileiro e Pensamento jurídico europeu. Lumen Juris. Rio de Janeiro. 2004.

De la Torre Rangel, Jesús Antonio. Los pobres y el uso del derecho. En El Otro Derecho No 6. ILSA. Bogotá. 1990.

Deleuze, Guilles. Guattari, Félix. Mil mesetas. Capitalismo y Esquizofrenia. Pre-textos. Valencia. 2010.

Duquelsky, Diego. La falsa dictomía entre Garantismo y activismo judicial. En DOXA, Cuadernos de Filosofía del Derecho, 41 (2018) ISSN: 0214-8676

Facio Montejo, Alda. Cuando el género suena cambios trae (una metodología para el análisis de género del fenómeno legal). ILANUD. San José. C.R. 1992. 
Faria, José Eduardo. Los temas ausentes en las reformas económicas latinoamericanas. En Portavoz $N^{\circ}$ 43. Julio 1995. ILSA. Bogotá. 1995.

Foucault, Michel. La verdad y las formas jurídicas. Editorial Gedisa S.A. Barcelona. 1992.

Gobille, Boric. Explotación, alienación y división social del trabajo. En https://vientosur.info/spip.php?article13490 2018.

Hegel, Friedrich. Principios de la filosofía del derecho. Edhasa. Barcelona. 1987.

Herrera Flores, Joquín. La reinvención de los Derechos Humanos, Atrapasueños. Andalucía. 2011.

Jacques P. Manuel. Educación para un Uso Alternativo del Derecho. Querqum. Documento de debate No 3. Santiago. 1986.

Jacques P. Manuel. Educar para los Derechos Humanos y las Estrategias de Defensa Jurídica desde la Sociedad Civil. Quercum. Documento de debate $\mathrm{N}^{\circ} 12$, Santiago de Chile. 1989.

Jacques P. Manuel. Una concepción metodológica del uso alternativo del derecho. El otro Derecho $\mathrm{N}^{\mathrm{o}}$ 1. Ilsa. 1988

Juristes Solidarites. Prácticas del derecho, producciones del derecho. Juristes Solidarités. Paris. 1993.

Lordon, Fréderíc. Capitalismo, deseo y servidumbre. Marx y Spinoza. Tinta limón. Buenos aires. 2015.

Losano, Mario. La ley y la azada: origines y desarrollo del Derecho Alternativo en Europa y en Sudamerica. En Direito alternativo Brasileiro e Pensamento jurídico europeu. Lumen Juris. Rio de Janeiro. 2004.

Medici, Alejandro. El malestar en la cultura jurídica. Ensayos críticos sobre políticas de derecho y derechos humanos. Edulp. La Plata. 2011.

Medici, Alejandro. Otros Nomos. Teoría del nuevo constitucionalismo latinoamericano. Centro de Estudios Jurídicos y Sociales Mispat. Universidad Autónoma de San Luis de Potosí. 2016.

Novoa Monreal, Eduardo. El Derecho como obstáculo al cambio social. Siglo XXI Editores. México. 1995.

Paz y Miño Cepeda Juan. América Latina: fin del ciclo progresista. https://firmas.prensa-latina.cu/index.php?opcion=ver-artic 
le\&cat=P\&authorID=129\&articleID=2390\&SEO=paz-y-minocepeda-juan-jose-america-latina-fin-del-ciclo-progresista 2017.

Rawls, John. Teoría de la Justicia. Fondo de Cultura Económica. México. 1995.

Rodríguez M, Eduardo. La producción social del derecho versus autonomía. En El Otro Derecho No 6. ILSA. Bogotá. 1990.

Rojas Hurtado, Fernando. Comparación entre las tendencias de los servicios legales en Noerteamética, Europa y América Latina. En El otro Derecho No 1. ILSA. Bogotá. 1988.

Saavedra, Modesto. Interpretación jurídica y uso alternativo del Derecho. En Sobre el Uso Alternativo del Derecho. Fernando Torres Editor. Valencia. 1978.

Sanchez, David. Seco, José. Suárez Juan. Estudio Preliminar. En Iusnaturalismo, Personalismo y Filosofía de la Liberación. Una visión Integradora. De la Torre Rangel, Jesus. Editorial MAD. Sevilla. 2005.

Santos, Boaventura de Sousa. Estado, Derecho y Luchas Sociales. Ilsa. Bogotá. 1991.

Shaviro, Steven. Estética aceleracionista: ineficiencia necesaria en tiempos de subsunción real. En Aceleracionismo. Estrategias para una transición hacia el postcapitalismo. Caja Negra Editora. Buenos Aires. 2017.

Srnicek, Nick. Williams, Alex. Inventar el futuro. Postcapitalismo y un mundo sin trabajo. Malpaso. México. 2018.

Wolkmer, Antonio Carlos. Introducción al pensamiento jurídico crítico. Editorial Académica. Sao Paulo. 1995.

Wolkmer, Antonio Carlos. Pluralismo Jurídico. Editorial Alfa Omega. Sao Paulo. 1994.

https://sites.google.com/site/diccionariodecenteno/c/conatus 